\title{
Juliana Proenço de Oliveira'
}

\section{Relendo Sophie Calle e Jean-Paul Thenot: sobre as dificuldades de descrever uma obra de arte}

Rereading Sophie Calle and Jean-Paul Thenot: on the difficulties of describing an art work

Relectures de Sophie Calle et Jean-Paul Thenot: sur les difficultés pour décrire une oeuvre d'art 


\section{Resumo}

Sophie Calle, em Purloined, expôs obras ausentes mediante descrições feitas por funcionários de museus; Jean-Paul Thenot, em Cent lectures de Marcel Duchamp, indagou, a cem pessoas, o que lhes evocavam imagens das obras de Duchamp. A fim de captar a percepção do público de arte em Porto Alegre, os exercícios de Calle e Thenot foram reproduzidos (com adaptações), tendo por objeto três obras da dupla de artistas Ío expostas em 2018 no Santander Cultural. Houve, assim, a aplicação de questionários a cem visitantes da instituição, convidando-os a descrever cada um dos trabalhos em uma palavra, bem como a realização de entrevistas orais com seus funcionários, nas quais se pediu que descrevessem as obras. Análises de conteúdo dos dados colhidos indicam, contudo, que a maioria deles não corresponde à definição epistemológica de "descrição". Este artigo propõe possíveis explicações desse resultado, como os meandros da relação entre imagem e palavra ou a influência de teorias tradicionais sobre interpretação da arte.

Palavras-chave: Descrição de obras de arte; Público de arte contemporânea; Relações entre imagem e palavra. Sophie Calle. Jean-Paul Thenot.

\section{Abstract}

Sophie Calle, in Purloined, exhibited absent works through descriptions made by museum employees; Jean-Paul Thenot, in Cent lectures de Marcel Duchamp, asked a hundred people what Duchamp's works evoked in them. In order to capture the public's perception of art in Porto Alegre, I reproduced the exercises of Calle and Thenot (with adaptations), having as object three works of the ĺo duo of artists exhibited in 2018 at Santander Cultural. I applied questionnaires to one hundred visitors of the institution, asking them to describe each of the works in a word. I also conducted oral interviews with Santander Cultural employees, who were invited to describe the works. Content analysis of the collected data indicates that most answers do not correspond to the epistemological definition of "description". This article proposes explanations for this result, such as the difficulties of the relation between image and word or the influence of traditional theories on the interpretation of art..

Keywords: Artwork description. Contemporary art audience. Relationship between image and word. Sophie Calle. Jean-Paul Thenot. 


\section{Résumé}

Sophie Calle, dans Purloined, a exposé des œuvres manquantes grâce aux descriptions fournies par des employés de musées; Jean-Paul Thenot, dans Cent lectures de Marcel Duchamp, a demandé à cent personnes qu'évoquait por eux reproductions photographiques des œuvres de Duchamp. Dans le but de capter la perception du public de l'art à Porto Alegre, les exercices de Calle et de Thenot ont été reproduits (avec quelques adaptations), ayant pour sujet trois œuvres du duo d'artistes Ío exposées en 2018 au Santander Cultural. Il y eut ainsi un questionnaire appliquée à cent visiteurs de l'institution, les invitant à décrire chacune des œuvres en un seul mot. De même, il y eut des entretiens oraux avec les employés du Santander Cultural, pendant lesquels il leur a été demandé de décrire les œuvres en question. Cependant, les analyses de contenu des données recueillies indiquent que la majorité ne correspondent pas à la définition épistémologique du mot «description». Cet article propose plusieurs réponses possibles expliquant ce résultat, ainsi que les subtilités de la relation entre l'image et le mot ou l'influence de théories traditionnelles sur l'interprétation de l'art..

Mots-clés: Description des œuvres d'art. Public d'art contemporain. Relations entre image et mot. Sophie Calle. Jean-Paul Thenot. 
A vontade de entender, de captar de algum modo, a percepção que "o público" tem da arte foi o ponto de partida deste estudo e representa, também, seu primeiro obstáculo; pois, assim "que fazemos algo mais do que contar entradas em museus [...], adverte-se que não existe 'o público'. Os visitantes de exposições [...] modificam ou recriam o significado em diferentes direções, não previstas por autores ou curadores" (CANCLINI, 2016, p. 209). Outra incerteza que logo se instaurou foi a de como interpelar os espectadores de arte - mesmo tomados individualmente, e não como uma ilusória massa homogênea; que tipo de questão formular: "o que você vê nesta obra?", mas o artístico não excede o visual?, "o que você pensa desta obra?", mas isto não a reduziria à esfera subjetiva? Convicta de que não havia caminho ideal a seguir, optei por reproduzir, em Porto Alegre, no ano de 2018, duas séries que propõem aproximações com aqueles que, normalmente, só observam: Purloined, de Sophie Calle, e Cent lectures de Marcel Duchamp, de Jean-Paul Thenot.

Em linhas gerais, Calle, na série referida, re-expôs obras de arte desaparecidas por meio de fotografias, junto com transcrições de descrições das peças, realizadas por funcionários dos museus onde elas eram guardadas antes de serem roubadas. ${ }^{2}$ Veja-se, a fim de melhor entender esse trabalho, texto introdutório exposto em Purloined (Turner):

Introdução - Em 28 de julho de 1994, Shade and Darkness-The Evening of the Deluge (Sombra e escuridão-A noite do Dilúvio) e Light and Colour (Goethe's Theory) -The Morning of the Deluge-Moses Writing the Book of Genesis (Luz e cor, Teoria de Goethe-A manhã do Dilúvio-Moisés escrevendo o Livro de Gênesis), de J.M.W. Turner, foram roubadas do Kunsthalle em Frankfurt. As duas pinturas estavam emprestadas da Tate em Londres. Em frente aos dois novos quadros de Turner que tomaram o lugar delas na Tate Britain, eu convidei curadores, guardas e outros membros da equipe de funcionários a descrever as obras desaparecidas. Após negociações secretas com a máfia iugoslava, Shade and Darkness voltou para Londres em julho de 2000, e Light and Colour próximo ao Natal de $2002^{3}$.

\footnotetext{
2 A tradução de "purloined" para o português é "roubado". Como jogos de palavras não são raros em se tratando de Sophie Calle, o título, a meu ver, aponta tanto para o status das peças (que, em sua maioria, não podem ser expostas pois foram furtadas de museus), como para o fato dela estar expondo obras feitas (materialmente) por outros artistas, como Picasso ou Turner, roubando-os, caso se adote um ponto de vista restritivo do que é "arte". A lógica, afinal, não é muito distante daquela empregada por Sherrie Levine, por exemplo.

3 Tradução livre do original: "Introduction - On July 28, 1994, Shade and Darkness-The Evening of the Deluge and Light and Colour (Goethe's Theory)-The Morning of the Deluge-Moses Writing the Book of Genesis, by J.M.W. Turner, were stolen from the Kunsthalle in Frankfurt. The two paintings were on loan from the Tate in London. In front of the two new Turners that took their place at the Tate Britain, I asked curators, guards, and other staff members to describe the missing works. After secret negociations with the Yugoslav mafia, Shade and Darkness came back to London in July 2000, and Light and Colour around Christmas 2002". Disponivel em: <https://www.perrotin.com/artists/Sophie_Calle/1/purloined-turner/27764>. Acesso 27 mai. 2019.
} 


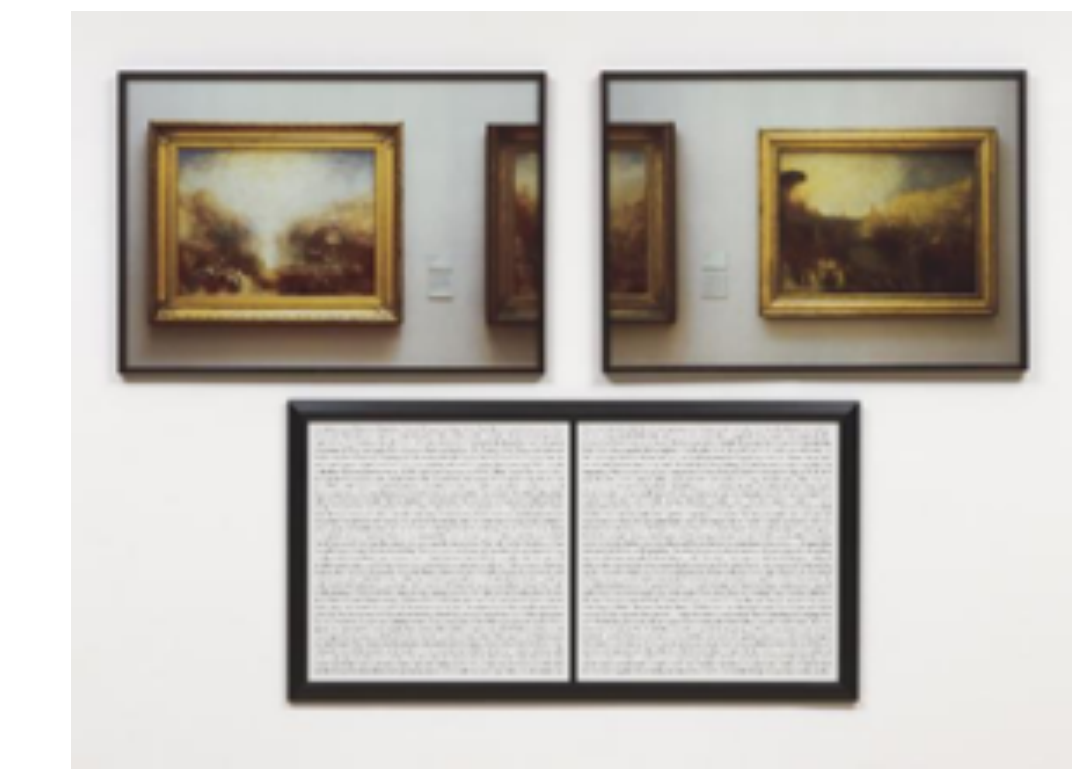

Figura 1. Sophie CALLE (1953)

Purloined (Turner), 1998-2013

Duas fotografias, impressões dye destruction sobre papel e litografia sobre papel, Dimensões variáveis. Tate Modern, Londres

Já Thenot - fundador do Collectif d'art sociologique (Coletivo de arte sociológica), junto com Hervé Fischer e Fred Forest - exibiu fotografias de algumas obras de Marcel Duchamp a cem pessoas, representantes da população francesa, indagando-lhes "O que evoca para você essa reprodução fotográfica?". A série, intitulada Cent lectures de Marcel Duchamp, consiste na apresentação das respostas obtidas (via de regra uma só palavra), percentualmente, e tomou a forma de livro, inclusive. ${ }^{4}$ Pondero que a pretensão de Thenot com a pesquisa não era, necessariamente, examinar a percepção dos entrevistados sobre arte; mas antes como suas concepções sobre objetos e cores, entre outros ${ }^{5}$, influenciam na fruição de obras, retiradas, de propósito, de seu contexto "oficial". Tanto que ele trabalhava com reproduções fotográficas - como não lembrar do Musée imaginaire de André Malraux? -, e a escolha por Duchamp e seus ready-mades tampouco soa ocasional.

\footnotetext{
4 Não tive acesso à publicação no Brasil. Ademais, entre os últimos acessos que fiz ao site de Thenot (<http://www.jeanpaulthenot.fr/>), em novembro de 2018, e o momento em que escrevo este artigo (maio de 2019), o endereço foi invadido e assumiu o duvidoso título Tienda online, les plus bas prix. Assim, parte das informações sobre 0 artista se baseiam em pesquisas e impressões anteriores, por ausência de outras opções.

5 Em série similar, intitulada Enquêtes interactives, Thenot formulava perguntas no molde "O que evoca para você?" sobre, por exemplo, cores e o preço de obras de arte. Em Cent lectures de Marcel Duchamp, ele também formulou questões sobre o ano em que os trabalhos mostrados foram produzidos, sobre o que evocam uma fonte e um urinol, etc. Enfim, trata-se de uma pesquisa sobre os cruzamentos e as camadas extra-artísticos que permeiam as obras.
} 


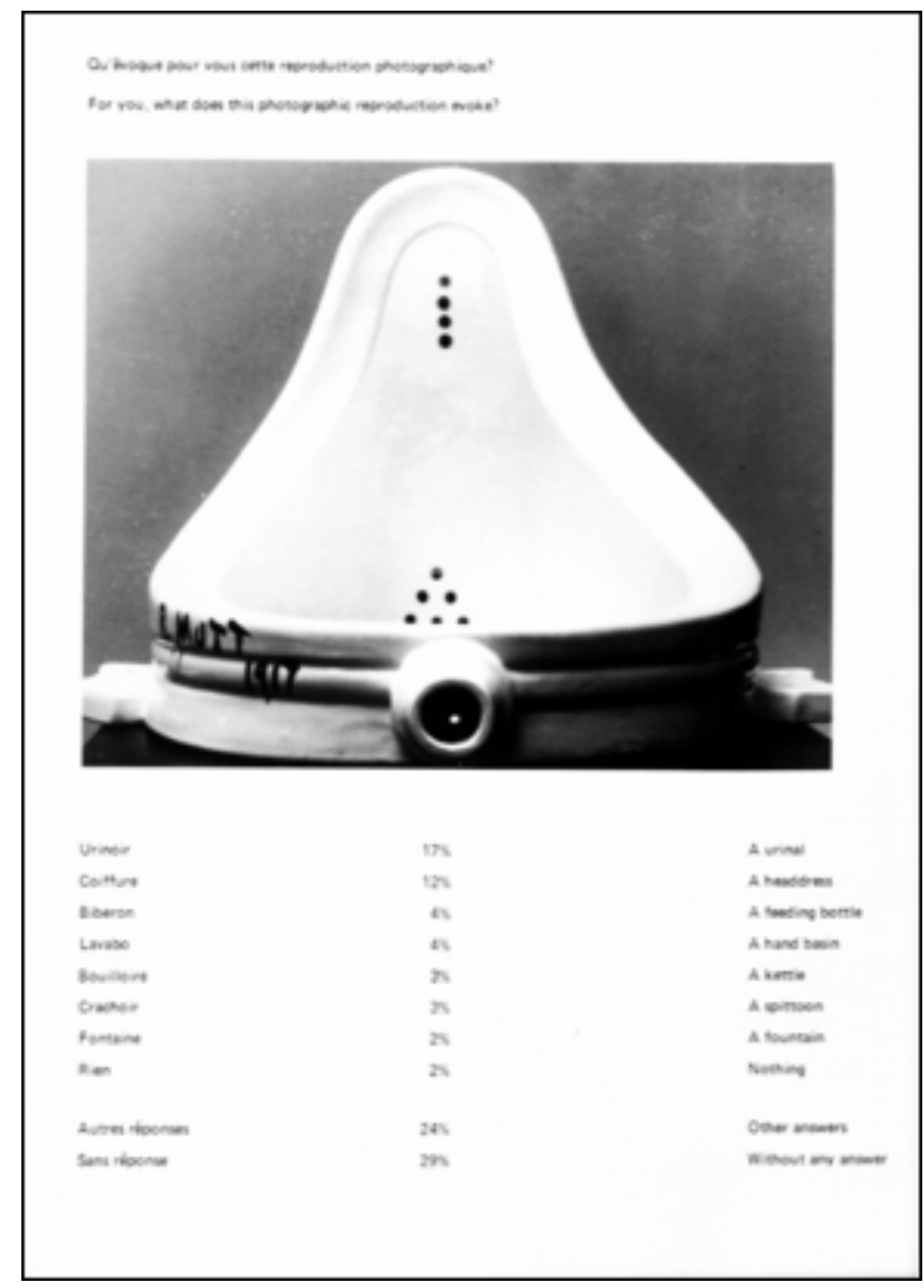

Figura 2. Jean-Paul THENOT (1943)

Cent lectures de Marcel Duchamp, 1974

Por vários motivos, não foi possível repetir exatamente os procedimentos de Calle e de Thenot. E algumas restrições dos artistas, como utilizar apenas obras ausentes, nem faziam sentido para mim. Não tive, além disso, acesso a relatos ou textos minuciosos sobre como eles desenvolveram seus trabalhos. Onde, afinal, Thenot aplicou os questionários? Em via pública? Com pessoas selecionadas? Quantos funcionários foram entrevistados por Calle? Ela apresentou outras perguntas, ou só os convidou a descrever? Assim, preenchi algumas lacunas com o que me pareceu mais conveniente. A primeira delas foi qual questionamento formular; entre as evocações de Thenot e as descrições de Calle, optei por estas. Demandar "descrições" soava um pedido mais neutro, científico até - ao menos em princípio. Depois, resolvi realizar a pesquisa no interior de um museu, partindo, pois, do pressuposto de que todos soubessem que ela era direcionada a obras de arte, com os ônus e bônus que isto traz. 


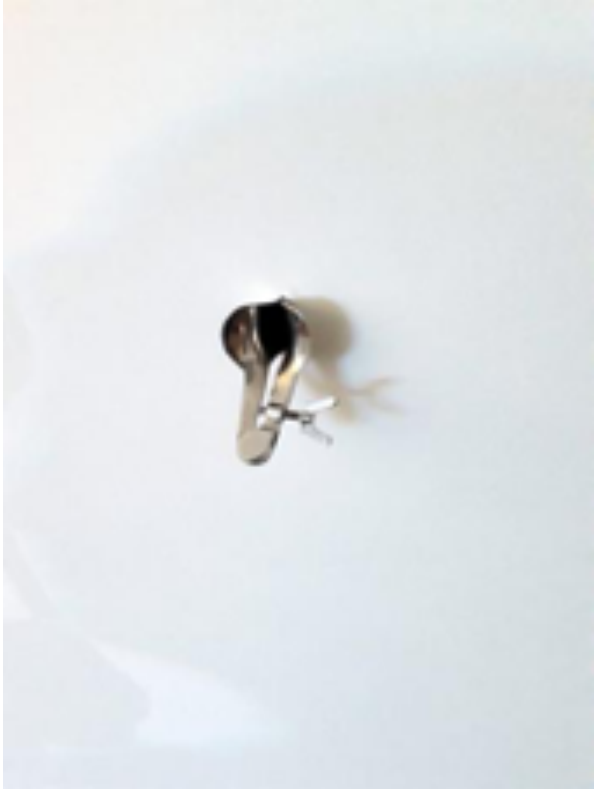

Figura 3. ÍO (Laura Cattani, 1980, e Munir Klamt, 1970)

Conjunção adversativa, 2018

Instalação: espéculo de aço inox em parede Coleção dos artistas

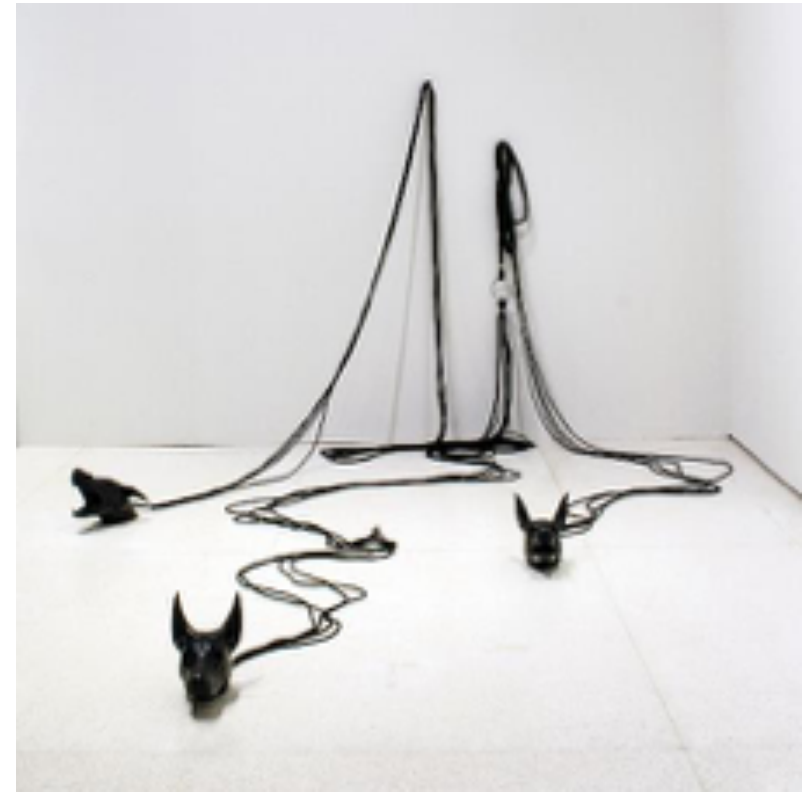

Figura 4. ÍO (Laura Cattani, 1980, e Munir Klamt, 1970) Qual é o nome do meu irmão?, 2018 Instalação: três cabeças de cachorro em bronze, cordas, presilhas de metal e livro Dimensões variadas Coleção dos artistas

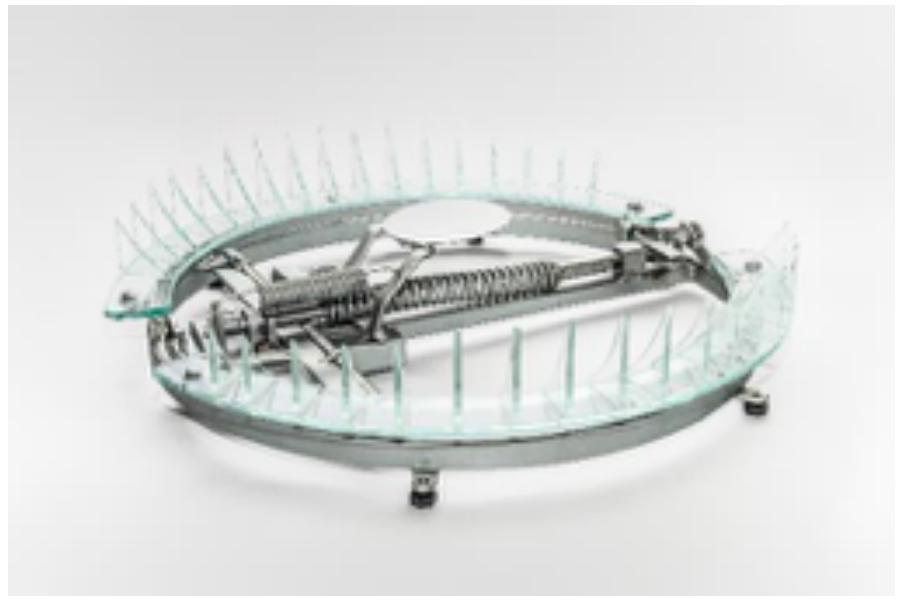

Figura 5. ÍO (Laura Cattani, 1980, e Munir Klamt, 1970)

Demônio pessoal, 2018

Escultura, metal e vidro, $70 \times 70 \times 25 \mathrm{~cm}$

Coleção particular

O local escolhido foi o Santander Cultural, em Porto Alegre ${ }^{6}$, especificamente a exposição RS XXI: Rio Grande do Sul experimental, com curadoria de Paulo Herkenhoff, que ocorreu entre 20 de junho e 29 de julho de 2018, marcando a reabertura da instituição, depois de quase um ano fechada, desde o imbróglio envolvendo a

6 Hoje a instituição se chama Farol Santander. 
mostra Queermuseu (no início de setembro de 2017). ${ }^{7}$ Selecionei, ainda, as três obras da dupla ĺo (Laura Cattani e Munir Klamt) expostas na RSXXI - Conjunção adversativa, Demônio pessoal e Qual é o nome do meu irmão? - como objetos de estudo. Feitas essas delimitações, desenvolvi um questionário inspirado em Thenot, com imagens dos três trabalhos e o comando "Descreva, em uma palavra, as seguintes obras", além de quatro perguntas para identificação dos participantes que não foram computadas na análise proposta aqui. ${ }^{8}$ Ele foi aplicado a cem visitantes que, estando diante das obras, aceitaram participar da pesquisa.

Em outro momento, pedi, na linha de Calle, a funcionários do Santander Cultural, que descrevessem as mesmas três obras, oralmente, em depoimentos gravados, numa sala da biblioteca (ou seja, em espaço diverso do da exposição). Não formulei nenhuma outra pergunta durante essas entrevistas, nem respondi a eventuais dúvidas dos participantes - como também pouco falei com aqueles que preencheram questionários. Nessa segunda "fase", foram mostradas imagens das obras (sem referência a seus títulos) aos funcionários da instituição, seguindo-se o convite a descrever. Permaneci uma tarde disponível a quem, sendo empregado de qualquer setor do Santander Cultural, quisesse participar do estudo; ao todo, seis pessoas compareceram. Tabelas com os resultados dos dois exercícios constam ao final do texto - isto é, trezentas palavras recolhidas nos questionários e transcrições de seis breves entrevistas. Os nomes de todos os participantes foram suprimidos.

7 Em breve síntese, a exposição foi prematuramente fechada após acusações, sobretudo em redes sociais, de que envolveria obras relacionadas a pedofilia e a profanação de símbolos religiosos. Aprofundar a questão extrapolaria o escopo deste artigo, mas aponto que a vontade de entender a percepção dos espectadores foi reforçada por esse episódio.

8 Ou seja, só analisei as "descrições" fornecidas, sem considerar dados de idade, profissão ou interesse específico em arte. Não ignoro que isto pode reforçar a idealização do "público", ao mesmo tempo, não há como abarcar tudo de uma vez só. 


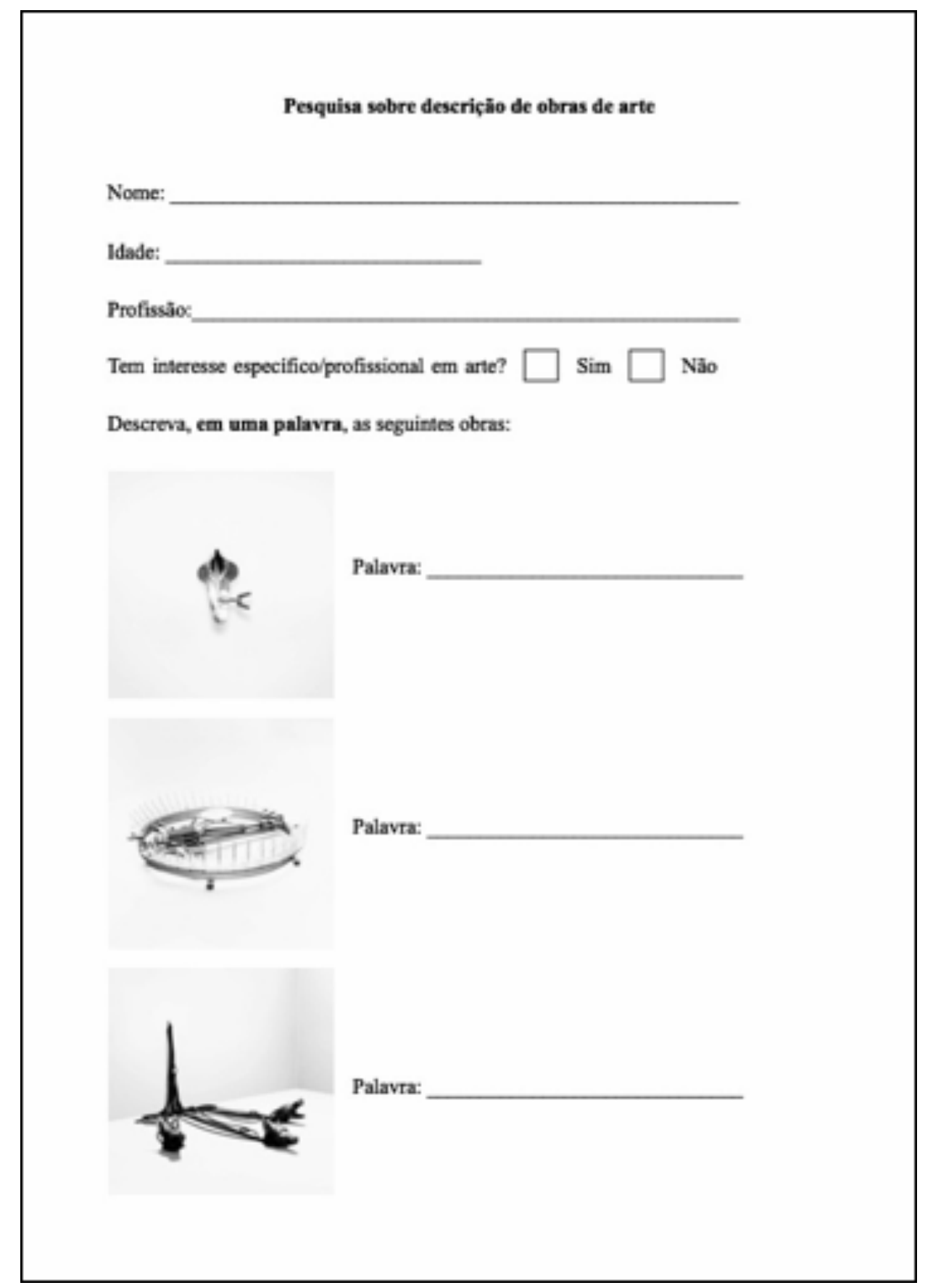

Passei, então, a realizar análises de conteúdo de tipo classificatório, com fulcro no livro de Laurence Bardin (2011, p. 65-72), a fim de examinar as possibilidades do material recolhido. Face à pergunta (ou instrução) feita aos participantes, a primeira categorização não poderia ser outra senão separar as respostas entre as que eram descrições (como demandado), e as que não eram. A base para tanto foi o artigo Describing and interpreting a work of art (Descrevendo e interpretando uma obra de arte, 1977) ${ }^{9}$, em que Robert J. Matthews diferencia, epistemologicamente, enunciados descritivos e interpretativos sobre obras de arte. Em resumo, trata-se de uma descrição o enunciado sobre a obra que pode ser avaliado como verdadeiro ou falso; já, se

9 Embora antiga, a tese apresentada no texto figura em diversos escritos posteriores sobre o assunto e, até onde me consta, não foi desmentida. 
não for possível avaliar o enunciado nem como verdadeiro, nem como falso, o que se tem é uma interpretação. Utilizo o trio de palavras da primeira linha dos resultados do questionário trazidos em anexo (I) para exemplificar a frase anterior: enquanto "Inox" é uma descrição de Conjunção adversativa (o espéculo acoplado à parede é feito de inox, logo o enunciado é verdadeiro) e "Cachorro" é uma descrição de Qual é o nome do meu irmão? (a obra representa cabeças de cães, logo o enunciado é verdadeiro); "Armadilha de humanos" é uma interpretação de Demônio pessoal, eis que não há, em princípio, dado objetivo que a confirme, nem que a negue. ${ }^{10}$

Aplicando-se essa categorização, só uma pequena porcentagem das respostas, tanto nos questionários quanto nas entrevistas orais, corresponde a descrições: $8 \%$, ou seja, 23 entre as 300 palavras recolhidas entre visitantes do Santander Cultural (as outras 277 se trata de interpretações), e 13\%, isto é, 10 entre as 75 unidades de significação em que separei o conteúdo das respostas dos funcionários da instituição. ${ }^{11}$ Seguem, abaixo, gráficos ilustrando as constatações trazidas nesse parágrafo; as cores mostradas nas figuras correspondem àquelas empregadas nas tabelas em anexo, de modo que é possível examinar os trechos e palavras atribuídos a cada uma das categorias. Proponho, nos limites deste artigo, desdobrar possíveis explicações dessa discrepância nos resultados. Por que, uma vez que o convite foi para descrever, a maioria dos participantes apresentou interpretações?

10 Veja-se que considerei as respostas com "Armadilha", apenas, como descrições, pela mesma lógica de "Cachorro", mas a observação "de humanos" dá outro sentido ao enunciado.

11 Para análise das entrevistas, optei por estabelecer unidades, que não correspondem a frases ou parágrafos, necessariamente. Elas foram delimitadas com base em seu sentido, ou tema; trata-se de excertos englobando uma só ideia (correspondente a uma das categorias do estudo). A nomenclatura se funda neste trecho de Bardin: "[...] o tema é a unidade de significação que se liberta naturalmente de um texto analisado segundo certos critérios relativos à teoria que serve de guia à leitura. $O$ texto pode ser recortado em ideias constituintes, em enunciados e em proposições portadores de significados isoláveis" (2011, p. 135). 
Questionários

\begin{tabular}{|l|c|}
\hline CATEGORIA & NRO DE PALAVRAS \\
\hline Descriçōes & 23 \\
\hline Interpretaçōes & 277 \\
\hline TOTAL & 300 \\
\hline
\end{tabular}
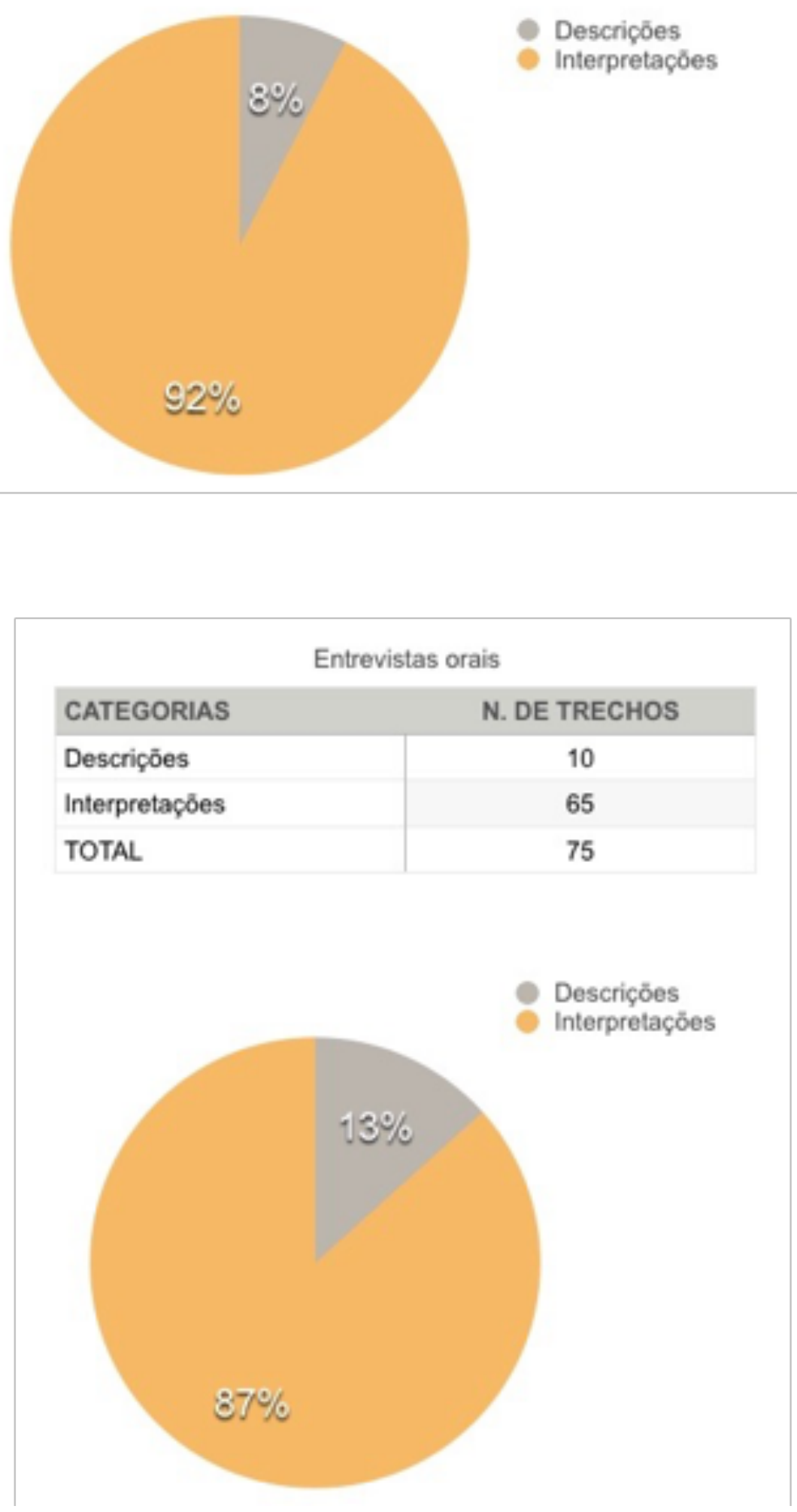
Uma hipótese evidente seria a de que boa parte dos entrevistados, senão todos, não deveria, nem teria como, conhecer a diferença epistemológica entre descrever e interpretar obras de arte. Creio que ela seja, em boa medida, acertada - mais adiante, comentarei a "utilidade" de se separar os dois procedimentos. De outro lado, quase nenhum dos participantes questionou a tarefa oferecida, respondendo, resta presumir, o que lhes pareceu mais "correto" diante da provocação feita por mim. No caso, o mais "correto", conforme a maioria, era não indicar aspectos objetivos ou consensuais, ou mesmo visuais, a respeito dos trabalhos (facilmente aferíveis como verdadeiros ou falsos, na linha do conceito de descrição aplicado aqui). Talvez isso se deva à presença das obras, ou de imagens delas, durante a elaboração das respostas pelos "descritores"; isto é, não faria sentido indicar características visíveis dos trabalhos, quando se está diante deles - ou de uma fotografia que os situa. Nesse norte, a escolha do comando de "descrever" por Calle se justificaria na ausência das obras; descreve-se aquilo que não se pode ver, uma espécie de retrato-falado das peças roubadas. As respostas obtidas nos exercícios que propus parecem guardar maior simetria com a questão de Thenot, "O que evoca para você?", mesmo porque as referências mais recorrentes dos participantes foram a sentimentos - "dor" é a palavra mais frequente entre os resultados, seguida de "medo". Embora os dados coIhidos aqui não a contemplem, uma reflexão válida (a ser desenvolvida) volta-se para o impacto dos termos de formulação da pergunta nas respostas do público: alguma mudança palpável ocorreria com a utilização de "interprete", em vez de "descreva", por exemplo? Existe uma questão, uma ou mais palavras incluídas nela, capaz de conduzir os resultados?

Para além dos meandros do discurso, deve-se reconhecer a existência de uma longa tradição, nos estudos da arte, de encará-la como algo além do que se vê, dependente de uma interpretação (ou várias). O próprio surgimento História da Arte está relacionado a teorias cujo cerne é a busca de significados ocultos nos mínimos detalhes de pinturas, vide a famosa iconografia de Erwin Panofsky. Em $A$ arte de descrever, Svetlana Alpers sustenta que a adoção de discursos visando a escavar sentidos sob a superfície pictórica (aquilo que se vê), tida como enganosa ${ }^{12}$, teria prejudicado o estudo das pinturas holandesas do século XVII, as quais, segundo a autora, são descritivas - isto é, representam o mundo visto, em vez de alguma alegoria ou narrativa a serem desvendadas, via interpretação. E o debate quanto a como encarar ou melhor traduzir obras de arte não se limita, de modo algum, às produções renascentistas.

O abandono dos meios usuais da arte (pintura e escultura) na contemporaneidade, sobretudo a partir dos anos 1960, nos Estados Unidos, aproximando-a de objetos "comuns", tornou ainda mais delicada a questão de como encará-la. Conforme Arthur Danto, filósofo atuante no contexto citado, buscar "uma descrição neutra é ver a obra como uma coisa e portanto não como obra de arte, já que uma condição analítica do conceito de obra de arte é que deva haver uma interpretação" (2005, p. 189). Se, por um lado, é fácil compreender a aplicação de tal frase às Brillo Boxes de Andy

12 'Longe de reproduzir o mundo 'real', diz essa tese, tais pinturas são abstrações materializadas, que pregam lições de moral ocultando-as sob encantadoras superfícies. Não acredite que o que você está vendo constitui a mensagem das pinturas holandesas" (ALPERS, 1999, p. 36). 
Warhol (que tanto inspiraram Danto), ela soa incompatível com outro movimento simultâneo à Pop Art; refiro-me ao Minimalismo, com sua posição marcadamente anti-ilusionista. A seguinte afirmação de Frank Stella bem resume a (nada simples) pretensão dos minimalistas: "O que você vê é o que você vê" (apud ARCHER, 2001, p. 50). Susan Sontag, no ensaio Contra a interpretação, aproxima-se em diversos pontos desse "espírito" minimal. A escritora, nesse sentido, diz que a "interpretação [...] constitui uma violação da arte. Torna a arte um artigo de uso, a ser encaixado num esquema mental de categorias" (SONTAG, 1987, p. 19), sugerindo que, como "a ênfase excessiva no conteúdo provoca a arrogância da interpretação, descrições mais extensas e mais completas da forma calariam. O que é necessário é um vocabulário - descritivo e não prescritivo - para as formas" (SONTAG, 1987, p. 21).

Mais recentemente, Georges Didi-Huberman, no livro $O$ que vemos, o que nos olha, comentando as ambições do Minimalismo, teceu tocante análise sobre a imensa dificuldade (para o observador) de tomar obras de arte, e até outras imagens e discursos ${ }^{13}$, como aquilo que se vê, e nada mais. Destaco o seguinte trecho:

[...] Se fosse preciso resumir brevemente os aspectos fundamentais reivindicados pelos artistas desse movimento [...] teríamos que começar por deduzir o jogo do que eles propunham a partir de tudo o que proscreviam ou proibiam. Tratava-se em primeiro lugar de eliminar toda ilusão para impor objetos ditos específicos, objetos que não pedissem outra coisa senão serem vistos por aquilo que são. O propósito, simples em tese, se revelará excessivamente delicado na realidade de sua prática. Pois a ilusão se contenta com pouco, tamanha é sua avidez: a menor representação rapidamente terá fornecido algum alimento - ainda que discreto, ainda que um simples detalhe - ao homem da crença (DIDI-HUBERMAN, 2010, p. 50).

Não há, de fato, como deixar de reconhecer que seria bastante chocante, assustador até, se os 106 participantes da pesquisa (computando-se os dois exercícios) tivessem indicado somente aspectos descritivos - visuais, óbvios, consensuais - a respeito das obras da dupla Ío, em consonância com a formulação da pergunta que lhes ofereci. Talvez o fascínio (ou a especificidade) da arte resida, justamente, na trama, nos desencontros e nos transbordamentos entre subjetivo e objetivo, imagem e palavra, ver, descrever, interpretar. Talvez o "valor" da obra repouse sobre um núcleo inefável, sobre uma impossibilidade fundamental de reduzi-la a, de abarcar seu todo com, palavras. São nesse sentido estas constatações de Jacques Derrida:

[...] Por princípio, nenhuma ficha técnica, nenhum catálogo jamais estarão completos. Assim como o próprio artista, cujos argumentos descritivos, epígrafe da obra, apenas complicam o propósito de suas associações, pontos de vista, contingências fantasmáticas, etc..., mesmo que ele escute: "é isso o que importa... além dos fantasmas". A dívida do autor, como a minha, são igualmente indescritíveis. Ninguém jamais terá esgotado as suas sobras (DERRIDA, 1978 , p. $274-275) .{ }^{14}$

130 capítulo inicial do escrito explora a ideia de uma "inelutável cisão do ver", sempre voltado, em parte, para nós mesmos, a partir do personagem Stephen Dedalus, do romance Ulysses, de James Joyce (DIDI-HUBERMAN, 2010, p. 29-35).

14 Tradução livre do original: "Aucune fiche technique, aucun catalogue ne s'en acquittera jamais, par principe. Pas plus que l'auteur lui-même, dont le cartuche descriptif, exergue dans l'oeuvre, vient compliquer l'objet de ses associations, points de vue, contingences phantasmatiques, etc..., même s'il entend 'ce qui 
Isto, de maneira alguma, significa que seja "inútil" o esforço de descrever obras de arte. ${ }^{15} \mathrm{~A}$ manifestação e o confronto de ideias e opiniões sobre os trabalhos enriquece, em muito, a experiência artística; a descrição é essencial nesses procedimentos. Primeiro, porque descrever, ater-se ao óbvio, em vez de submergir nos próprios pensamentos, por questões subjetivas (na linha de Didi-Huberman) ou pela vontade de arrancar significados ocultos; deixar-se estar presente para e com a obra - outra ambição dos minimalistas - é um exercício de generosidade e pode render descobertas impressionantes. O olhar atento, sem pressa e sem pressão de produtividade, deveria ser a base da percepção da arte. Segundo Jorge Coli, "Frequentar uma obra é, antes de tudo, um ato de interesse. Ouvir uma sinfonia é escutá-la e reescutá-la; olhar um quadro é examiná-lo, observá-lo, detalhá-lo. Conheço poucos exercícios tão fecundos quanto descrever simplesmente uma pintura [...]" (2013, p. 123). Depois, porque a falha na maneira como é comunicada pode prejudicar até a mais brilhante interpretação de uma obra de arte. Assim, a base do desenvolvimento (escrito ou falado) da interpretação deve ser a descrição, a fim de que o receptor possa encontrar um dado objetivo, visível, que amarre o significado atribuído, viabilizando-lhe posicionar-se diante daquilo que foi escrito sobre tal obra de arte. ${ }^{16}$

Nunca é fácil, para o historiador ou o crítico de arte, confrontar-se com o público, eis que isto o tira de sua posição de autoridade, mas é um incômodo necessário. O objetivo deste estudo nunca foi o de julgar as respostas dos participantes como "certas" ou "erradas". Ao mesmo tempo, seria temerário afirmar que toda e qualquer percepção sobre arte é válida, já que isto equivaleria a legitimar posições que descambam, muitas vezes, em censura (não por acaso, este estudo se seguiu à polêmica da exposição Queermuseu). Cabe trazer o seguinte comentário de Anne D'Alleva: "[...] história da arte não é opinião, é interpretação, que pode ser melhor caracterizada como uma opinião embasada e bem informada" (2010, p. 74). Diante dos ataques recentes sofridos pela arte no Brasil - e da ausência de perspectiva de melhora -, mostra-se indispensável incluir e valorizar a visão do público nas pesquisas teóricas e práticas; e também refletir a respeito da forma como se comunica o conhecimento produzido na área, no que a instrumentalização de descrições e interpretações pode ser bastante útil. Sejamos inefáveis, mas não herméticos.

\section{Referências}

ALPERS, Svetlana. A arte de descrever: a arte holandesa no século XVII. São Paulo: Editora da Universidade de São Paulo, 1999.

\footnotetext{
importe... par-delà les fantasmes'. La dette de l'auteur, comme la mienne, sont aussi indescriptibles. Personne ne sera jamais quitte devant ces restes".

15 Lembro aqui de uma citação de Goethe, trazida por Pierre Bourdieu, ao comentar sobre como os estudos sociológicos da arte ofendiam certos estudiosos, que se agarravam ao seu aspecto inefável para rebatê-los: "Nossa opinião é de que convém ao homem supor que há algo de incognoscivel, mas ele não deve colocar limite à sua busca" (BOURDIEU, 1996, p. 13).

16 "A descrição é um elemento essencial da crítica. Descrições precisas de uma obra de arte são fundamentais a uma interpretação que virá a seguir [...]. se um objeto é descrito de um modo impreciso e então é feito um julgamento com base nesta descrição ruim, o julgamento decorrente será suspeito" (BARRET, 2014, p. 92).
} 
ARCHER, Michael. Arte contemporânea: uma história concisa. São Paulo: Martins Fontes, 2001.

BARDIN, Lawrence. Análise de conteúdo. São Paulo: Edições 70, 2011.

BARRETT, Terry. A crítica de arte: como entender o contemporâneo. 3 ed. Porto Alegre: AMGH, 2014.

BOURDIEU, Pierre. As regras da arte. São Paulo: Companhia das Letras, 1996.

CANCLINI, Nestor García. A sociedade sem relato: antropologia e estética da iminência. São Paulo: Editora da Universidade de São Paulo, 2016.

COLI, Jorge. O que é arte. São Paulo: Brasiliense, 2013.

D’ALLEVA, Anne. How to write art history. 2 ed. Londres: Laurence King Publishing Ltda., 2010.

DANTO, Arthur. A transfiguração do lugar-comum: uma filosofia da arte. São Paulo: Cosac Naify, 2005.

DERRIDA, Jacques. La vérité en peinture. Paris: Flammarion, 1978.

DIDI-HUBERMAN, Georges. O que vemos, o que nos olha. São Paulo: Editora 34, 2010.

MATTHEWS, Robert J. Describing and interpreting a work of art. In: The Journal of Aesthetics and Art Criticism, vol. 36, n. 1, autumn 1977, p. 5-14. Disponível em: <https://www.jstor.org/stable/430744? read-now=18refreqid=excelsior\%3Acc6986c9da5d11582b e33e3b1136c2cc\&seq=1\#page_scan_tab_contents>. Acesso 01 dez. 2018.

PERROTIN. Sophie Calle | Purloined: Turner, 1998-2013. Disponível em: <https://www. perrotin.com/artists/Sophie_Calle/1/purloined-turner/27764>. Acesso 27 mai. 2019.

SONTAG, Susan. Contra a interpretação. Porto Alegre: L\&PM, 1987.

THENOT, Jean-Paul. Site oficial do artista. Disponível em: <http://www.jeanpaulthenot.fr>. Acesso 31 out. 2018.

\section{Anexos}

I - Respostas dos questionários: 


\begin{tabular}{|c|c|c|}
\hline Conjunção adversativa & Demónio pessoal & $\begin{array}{c}\text { Qual é o nome do meu } \\
\text { irmão? }\end{array}$ \\
\hline Inox & Armadilha de humanos & Cachorro \\
\hline O nascimento & Você erra se quiser & Guardião do infinito \\
\hline Inovador & Criativo & Diferenciado \\
\hline Intrusiva & Exótica & Impressionante \\
\hline Enigmático & Curioso & Inusitado \\
\hline Lacre & Tempo & Conexão \\
\hline Medicina & Espinhos & Limite \\
\hline Profundidade & Armadilha & Presos \\
\hline Constrangimento & Natureza & Expressão/sentimentos \\
\hline Sexualidade & Superioridade & Posse \\
\hline Bico & Corredor & Anúbis \\
\hline Ferramenta & Armadilha & Impactante \\
\hline Vagina & Armadilha & Feroz \\
\hline Sexo & Catapulta & Sadomasoquismo \\
\hline Conexão & Vulnerabilidade & Realidade \\
\hline Ferramenta & Armadilha & Selvagem \\
\hline Estranho & Presa & Dobermann \\
\hline Duvidoso & Urso & Cérbero \\
\hline Dúvida & Caça & Proteção \\
\hline Funcional & Surpreendente & Mitológicos \\
\hline Monumento & Espelho & Cerebelo \\
\hline Função & Máquina & Linguagem \\
\hline Vulva & Armadilha & Confuso \\
\hline Ressignificação & Sincronismo & Impressão \\
\hline Minimalista & Utilitário & Floresta \\
\hline Profundo & Circular & Segurança \\
\hline Túnel & Incógnita & Surreal \\
\hline Natureza & Civilização & Cérbero \\
\hline
\end{tabular}




\begin{tabular}{|c|c|c|}
\hline Conjunção adversativa & Demónio pessoal & $\begin{array}{c}\text { Qual é o nome do meu } \\
\text { irmão? }\end{array}$ \\
\hline Esquisito & Olhar & Cães \\
\hline Penetração & Dentada & Caça \\
\hline Rigidez & Fragilidade & Autoproteção \\
\hline Alargador & Dor & Dobermanns \\
\hline Dor & Destruição & Medo \\
\hline Dor & Dor & Dor \\
\hline Feminino & Dor & Prisão \\
\hline Dolorida & Bleh & Agoniante \\
\hline Visibilidade & Dor & Limite \\
\hline Ligação & Dor & Medo \\
\hline Vazio & Dor & Medo \\
\hline Sexual & Dor & Crueldade \\
\hline Angústia & Dor & Prisão \\
\hline Violência & Dor & Odio \\
\hline Dor & Marcas & Censura \\
\hline Vagina & Humanos & Prisão \\
\hline Aprisionado & Torturado & Encurralado \\
\hline Intimidador & Lobo & Caçador \\
\hline Misterioso & Estranho & Apavorante \\
\hline Chafariz & Prisão & Perseguição \\
\hline Maternidade & Horror & Busca \\
\hline Invasão & Medo & Incapacidade \\
\hline Invasão & Predador & Medo \\
\hline Desconhecido & Perigo & Ausência \\
\hline Intrigante & Quero & Medo \\
\hline Intrigante & Estranho & Medo \\
\hline Intimo & Perigo & Amedrontador \\
\hline Perereca & Ratoeira & Angústia \\
\hline Gancho & Armadilha & Prisão \\
\hline
\end{tabular}




\begin{tabular}{|c|c|c|}
\hline Conjunção adversativa & Demónio pessoal & $\begin{array}{l}\text { Qual é o nome do meu } \\
\text { irmão? }\end{array}$ \\
\hline Força & Prisão & Sofrimento \\
\hline Cérvix & Armadilha & Cruella \\
\hline Incompreensão & Trituração & Afeto/barreira \\
\hline Violência & Travamento & Imobilidade \\
\hline Agoniante & Desafiador & Curioso \\
\hline Estranheza & Agonia & Ataque \\
\hline Medicina & Angústia & Morte \\
\hline Gineco & Nervoso & Fúria \\
\hline Sarcástico & Perigoso & Complexo \\
\hline Invasivo & Sangue & Horror \\
\hline Invasivo & Trapaça & Surgimento \\
\hline Desautonomia & Emboscada & Instinto \\
\hline Interior & Caçada & Dificuldades \\
\hline Intimo & Caçada & Prisão \\
\hline Instigante & Aflição & Assustador \\
\hline Tortura & Ataque & Assustador \\
\hline Abstrato & Armadilha & Perigo \\
\hline Castigo & Sofrimento & Perigo \\
\hline Medicinal & Boicote & Sobriedades \\
\hline Intimidade & Perigo & Controle \\
\hline Estranho & Voraz & Dominação \\
\hline Apoio & Insegurança & Intolerância \\
\hline Agonia & Tortura & Perseguição \\
\hline Curiosidade & Atenção & Insegurança \\
\hline Curiosidade & Sinergia & Agonia \\
\hline Segredos & Beautification & Ameaça \\
\hline Intrigante & Covardia & Raiva \\
\hline Curioso & Perigo & Segurança \\
\hline Estranho & Perigo & Feroz \\
\hline
\end{tabular}


II - Respostas das entrevistas orais:

\begin{tabular}{|c|c|}
\hline Obra & Descriçöes - Descritor n. 01: \\
\hline Conjunção adversativa & Objeto perigoso, que machuca [dor], que provoca repulsa. \\
\hline Demônio pessoal & Objeto que machuca [dor]. \\
\hline $\begin{array}{l}\text { Qual é o nome do meu } \\
\text { irmäo? }\end{array}$ & Medo, grotesco. \\
\hline
\end{tabular}




\begin{tabular}{|c|c|}
\hline Obra & escritor \\
\hline Comentário geral & 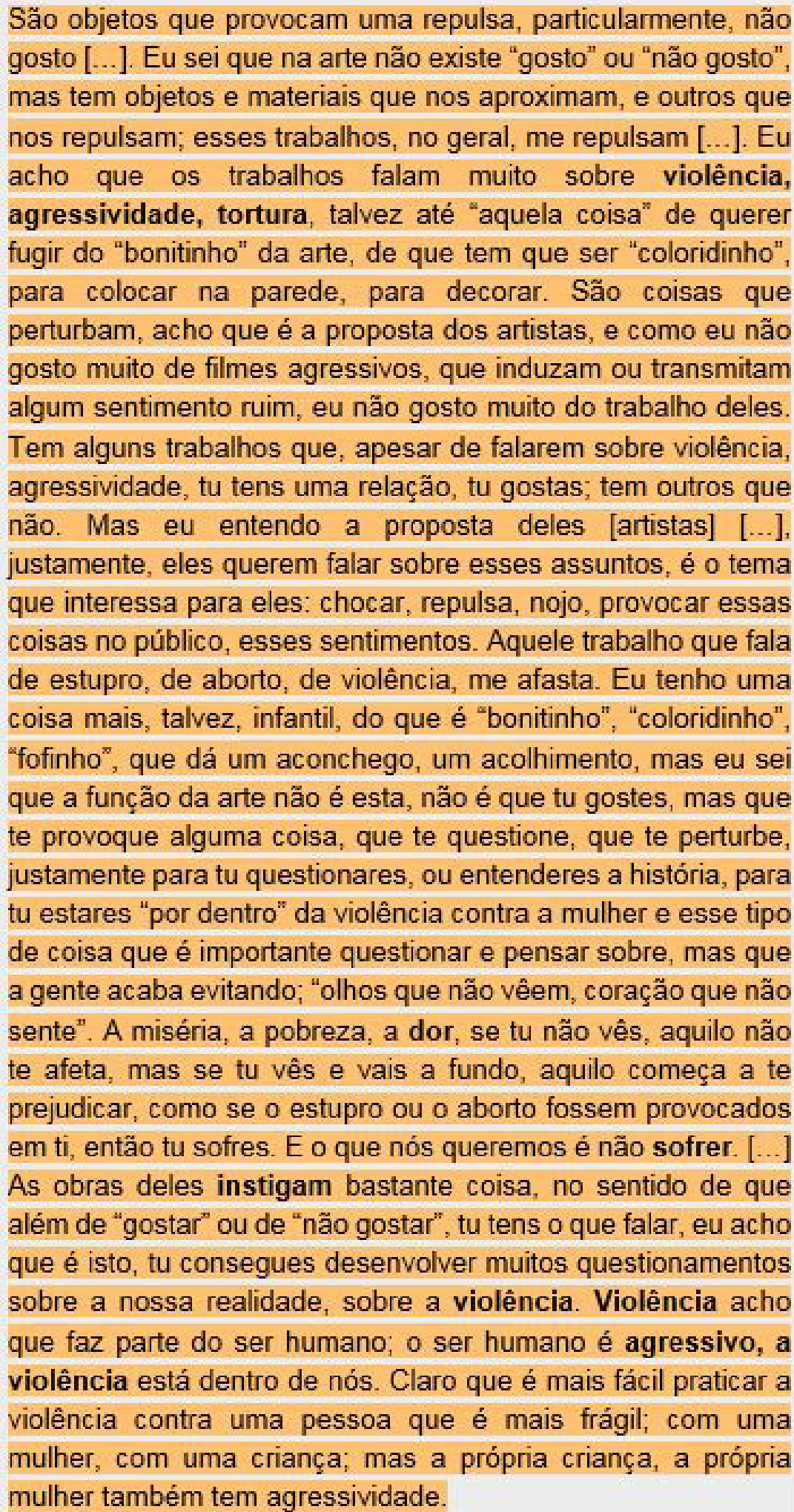 \\
\hline
\end{tabular}




\begin{tabular}{|c|l|}
\hline \multicolumn{1}{|c|}{ Obra } & \multicolumn{1}{|c|}{ Descriçöes - Descritor n. 02: } \\
\hline Conjunção adversativa & $\begin{array}{l}\text { Ready-made, me parece uma "daquelas coisas" de } \\
\text { descontextualização [ressignificação]. Sempre me remete ao } \\
\text { [Marcel] Duchamp, eu acho sempre muito parecido. Eu fico } \\
\text { pensando que o "cara" [Duchamp] fez isto há tanto tempo e fez } \\
\text { tão bem, que insistem tanto em se aproximar, mas ninguém vai } \\
\text { chegar perto. Acho que já passou aquele momento, nunca vi } \\
\text { uma "grande sacada". Agora este sim [Duchamp] foi o melhor } \\
\text { que eu vi. }\end{array}$ \\
\hline Demônio pessoal & $\begin{array}{l}\text { Frágil. Como eu trabalho há muito tempo com montagem de } \\
\text { exposições... E [...] um trabalho que fica no chão, baixo, } \\
\text { perigoso, oferece risco pro público, a obra em si corre muito } \\
\text { risco. Eu acabo tendo uma visão muito técnica, quando eu } \\
\text { olho "aquela coisa" no chão, eu já me preocupo. }\end{array}$ \\
\hline Qual é o nome do meu \\
irmäo? & $\begin{array}{l}\text { Esse [trabalho] eu já acho mais legal. Ele é mais agressivo. } \\
\text { Mas eu acho ele, de certa maneira, caricato, porque, na } \\
\text { verdade, ele não vai te atacar [ataque], [...] ele tem uma certa } \\
\text { empatia. Ele pretende ser assustador, mas não assusta tanto } \\
\text { quanto gostaria, é o que me parece. }\end{array}$ \\
\hline
\end{tabular}

\begin{tabular}{|l|l|}
\hline \multicolumn{1}{|c|}{ Obra } & Descriçöes - Descritor n. 03: \\
\hline Conjunçäo adversativa & $\begin{array}{l}\text { E um trabalho novo da lo, que eu não conhecia, mas, para mim, } \\
\text { sempre existe [nas obras] um texto subliminar, alguma coisa } \\
\text { que está em uma camada não muito acessivel. Há um segredo, } \\
\text { uma chave para encontrar isto. Até pelo fato de ela estar na } \\
\text { parede, ela evoca, justamente, isto, um dispositivo conectado } \\
\text { na parede do espaço expositivo, que não está pendurado, está } \\
\text { anexado, ele interfere, ele entra dentro desse espaço, quase } \\
\text { como um site specific. Um dispositivo que interfere, que } \\
\text { arranha, que machuca [dor] esse espaço, e cria um corpo, uma } \\
\text { amálgama entre um objeto cotidiano, simples, com } \\
\text { funcionalidades diversas, mas ali, ele perde a sua função } \\
\text { objetiva, específica, ele passa a ser um dispositivo de ruído, de } \\
\text { incômodo, de relação. }\end{array}$ \\
\hline
\end{tabular}




\begin{tabular}{|c|c|}
\hline Obra & Descriçōes-Descritor n. 03: \\
\hline Demônio pessoal & $\begin{array}{l}\text { Esse [trabalho] também é um apontamento de discurso que } \\
\text { está lá, engendrado nesse mecanismo. Ele me parece justapor } \\
\text { agressividade, força, delicadeza, fragilidade. E uma } \\
\text { armadilha, mais uma vez, um dispositivo, uma ferramenta, um } \\
\text { instrumento reconhecível; uma armadilha para prender lobos, } \\
\text { ou feras. Como eu já conhecia esse trabalho um pouco mais } \\
\text { também, se ela apreende isto que ela parece esperar... Tem a } \\
\text { coisa do tempo também, do objeto em suspensão, } \\
\text { aguardando, uma armadilha mesmo, que aguarda } \\
\text { pacientemente a sua presa. Mas, ao menos tempo, ela é } \\
\text { fadada à própria morte, no momento em que ela se fechar... } \\
\text { Se a presa é frágil, ela também assume, nesse instante, a } \\
\text { própria fragilidade: ambos morrem, ambos se prendem, se } \\
\text { amalgamam juntos, mais uma vez [como na obra anterior], se } \\
\text { unem, se corporificam. }\end{array}$ \\
\hline $\begin{array}{c}\text { Qual é o nome do meu } \\
\text { irmäo? }\end{array}$ & $\begin{array}{l}\text { São três cabeças, três cães... [...] Mais uma vez, esse trabalho } \\
\text { estabelece uma relação com o espaço. Eles [os cães] estão } \\
\text { contidos, de novo, existe a presença dessa agressividade, } \\
\text { disso que é ameaçador, mas contidos por essa - eu não sei } \\
\text { que material é aquele - corda, que os prende, subtraindo dali o } \\
\text { corpo. Talvez nesses cães, que parecem raivosos, a anatomia } \\
\text { desses bichos... Para que nós percebamos que um animal, no } \\
\text { caso um cão, esstá tendo uma atitude agressiva, isso tudo vai } \\
\text { acontecer na cabeça. Ele não vai comunicar isto com as patas, } \\
\text { ou com nenhuma parte do corpo. Parece que a escolha da } \\
\text { cabeça é, justamente, por isso, essa parte da anatomia que vai } \\
\text { comunicar essa intencionalidade, mas que está contida. Eles } \\
\text { parecem pretender direções diferentes; ao mesmo tempo, eles } \\
\text { só se acessariam entre eles mesmos, se eles pudessem se } \\
\text { movimentar, de fato, só conseguiriam alcançar eles mesmos } \\
\text { [prisão, limite]. Há uma espécie de conluio, de cumplicidade } \\
\text { não é parceria simplesmente. Se não me engañ o título é } \\
\text { "Qual é o nome do meu irmão?". Ė muito interessante porque } \\
\text { "irmão" também tem essa ideia de cumplicidade, tem outras } \\
\text { "historinhas". A lo busca muita leitura também, tem muitas } \\
\text { coisas da mitologia e da literatura presentes nos trabalhos } \\
\text { deles... E traduzir isto em imagem, em instalação, em situação } \\
\text { visual é, realmente, um desafio, e acho que eles conseguem } \\
\text { muito bem isto. Um texto, lido por mais pessoas, sofre } \\
\text { possibilidades de leitura, interpretações diferentes, é rico por } \\
\text { isto. }\end{array}$ \\
\hline
\end{tabular}




\begin{tabular}{|c|l|}
\hline Obra & \multicolumn{1}{c|}{ Descriçöes - Descritor n. 04: } \\
\hline Conjunção adversativa & $\begin{array}{l}\text { Objeto super-identificá́xel, ao menos para as mulheres, que } \\
\text { dentro do espaço expositivo tem uma outra conotação. }\end{array}$ \\
\hline Demônio pessoal & $\begin{array}{l}\text { Objeto bastante atraente, de difícil entendimento, mas que } \\
\text { revela no seu interior, quanto tu te dás conta do centro, um } \\
\text { pouco de mim, um pouco da pessoa que está visualizando, ali } \\
\text { dentro daquele local complexo [espelho]. }\end{array}$ \\
\hline $\begin{array}{c}\text { Qual é o nome do meu } \\
\text { irmäo? }\end{array}$ & $\begin{array}{l}\text { Trabalho bastante forte e quase agressivo, remete a muitas } \\
\text { coisas de violência. }\end{array}$ \\
\hline
\end{tabular}

\begin{tabular}{|c|c|}
\hline Obra & Descriçöes - Descritor n. 05: \\
\hline Comentário geral & $\begin{array}{l}\text { Eu tenho que falar sobre o que eu achei da obra? A minha } \\
\text { impressão? } \\
R \text { : Como tu quiseres, é livre. }\end{array}$ \\
\hline Conjunção adversativa & $\begin{array}{l}\text { Eu gosto dela [da obra], porque ela é um pouco rebelde... } \\
\text { Como a dupla [io] trabalha com questões de transgressão, eu } \\
\text { acho que foi proposital eles terem utilizado uma obra com esse } \\
\text { tipo de referência, uma vagina, num espaço como o Santander } \\
\text { [Cultural] hoje, em função do que ocorreu [com a exposição } \\
\text { Queermuseu]... Por causa disto, eu gostei. }\end{array}$ \\
\hline Demônic & $\begin{array}{l}\text { Essa [obra] eu conheço também, é Demônio pessoal. Eu não } \\
\text { gosto muito dessa obra, são questões pessoais... Não é por } \\
\text { causa do tema dela, nem do que ela quer dizer. Mas eu acho } \\
\text { que não ficou legal o objeto naquele sentido e a referenciação } \\
\text { que se fez em relação ao título do trabalho. Por isto, eu não } \\
\text { gostei muito, achei que não ficou muito objetivo. Eu sei que não } \\
\text { precisa ser objetivo, mas como eu sou bibliotecário, eu tento } \\
\text { buscar objetividade em tudo. Então, eu não gostei disto. } \\
\text { Sempre que eu vou visitar museus, obras de arte, eu tento criar } \\
\text { vínculos que sejam objetivos para mim, e eu não vi uma ligação } \\
\text { muito perfeita nessa obra. }\end{array}$ \\
\hline $\begin{array}{l}\text { Qual é o nome do meu } \\
\text { irmão? }\end{array}$ & $\begin{array}{l}\text { Essa [obra] eu também gosto, porque ela é pulsante, parece } \\
\text { que a obra está em movimento. Os cachorros no chão, com as } \\
\text { cordas; a impressão é de que, realmente, os cachorros, se não } \\
\text { fossem as cordas, eles iriam pular "na tua cabeça". Há essa } \\
\text { questão de movimento. }\end{array}$ \\
\hline
\end{tabular}




\begin{tabular}{|c|c|}
\hline Obra & Descriçōes - Descritor n. 06: \\
\hline Conjunção adversativa & $\begin{array}{l}\text { Essa obra parece um instrumento médico, cirúrgico, me faz } \\
\text { lembrar... Não conheço muita coisa sobre medicina... Me faz } \\
\text { lembrar um tipo de alargador, usado para se abrir cortes } \\
\text { cirúrgicos, ou até para obstetrícia... Não sei, já vi coisas } \\
\text { parecidas em seriados médicos (riso). E esse objeto estáa } \\
\text { inserido direto na parede da sala expositiva, como que } \\
\text { forçando a entrada através de uma fenda, que antes não existia } \\
\text { nesse espaço. Passa uma ideia de penetração forçada } \\
\text { abertura forçada de uma passagem dentro do espaço } \\
\text { expositivo. }\end{array}$ \\
\hline Demônio pessoal & $\begin{array}{l}\text { Essa obra me parece ser um tipo de armadilha usada para } \\
\text { caçar animais de grande porte na floresta. Mas ela foi feita } \\
\text { com um material fora do normal, pelo que eu sei, de vidro, e } \\
\text { não de metal, como normalmente é feito. A sensação que eu } \\
\text { tenho em relação a ela... Eu não tenho muito contato, não li ou } \\
\text { estudei sobre a obra, então o que eu tenho é uma sensação } \\
\text { como público mesmo de arte contemporânea, mais do que } \\
\text { como uma pessoa que trabalhou na exposição nesse caso... } \\
\text { Ela passa [a obra], apesar dessa aparência geral de armadilha } \\
\text { ou de agressão, uma sensação de fragilidade, em função do } \\
\text { material com que ela foi feita, vidro. Ela é praticamente um } \\
\text { objeto inviável, que não se realiza no seu propósito original, } \\
\text { mas que está modificado pela construção que eles [os artistas] } \\
\text { fizeram desse objeto. }\end{array}$ \\
\hline $\begin{array}{l}\text { Qual é o nome do meu } \\
\text { irmäo? }\end{array}$ & $\begin{array}{l}\text { Essa última obra é, para mim, a mais misteriosa das três, na } \\
\text { verdade, para leitura da imagem, são três cabeças de } \\
\text { cachorro, colocadas junto ao chão, cada uma delas sai de um } \\
\text { tipo de guia ou coleira, e essas guias estão presas juntas, } \\
\text { penduradas por uma argola na parede da sala expositiva. } \\
\text { Quando eu tive a oportunidade de visitar a exposição, eu } \\
\text { acabei pensando no arquétipo do Cérbero, do cachorro de três } \\
\text { cabeças, mas não consegui muito construir uma narrativa } \\
\text { desse obra em relação às outras para além disto. Talvez tenha } \\
\text { "a ver" com a ideia de entrada existente na primeira obra, ou } \\
\text { de fenda, ou de espaço no qual se entra de uma maneira } \\
\text { forçada... Esse bicho está ali como um tipo de guardião, uma } \\
\text { função tanto de cachorros normais, quanto do Cérbero. }\end{array}$ \\
\hline
\end{tabular}

